\section{GET SET FOR BDTA SHOWCASE}

The BDTA Dental Showcase will be taking place in London this year, bringing you the largest selection of dental products, services and technologies all under one roof.

There will also be the chance to obtain CPD hours by attending the complimentary daily seminars. It takes place 14-16 October 2010 at ExCel in London.

To register in advance for your complimentary ticket visit www.dentalshowcase. com/visit, call the registration hotline on 01494 729959 or text your name, address, occupation and GDC number to 07786206276 . Advance registration closes on 1 October 2010 . On-theday registration will cost $\mathfrak{E} 10$ per person. Reader response number 50

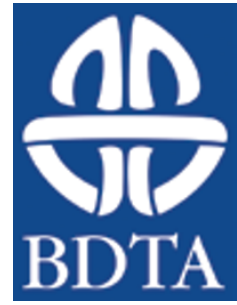

\section{DISEASE \\ MANAGEMENT}

You are invited to attend an innovative practical oral medicine day for the dental team on 23

September 2010. Learn how each team member can contribute to the quality of life of patients with oral mucosal disease. From oral cancer to HIV infection, a broad understanding of the disease and its impact on patients' lives will help you deliver excellent care.

The programme includes the non-surgical management of patients with head and neck cancer; radiation induced hyposalivation and mucositis - effects, prevention and management; restoration and rehabilitation; the role of the DCP in the care of a terminally ill HIV-infected patient; and the infected dentist, patient records and confidentiality.

This day is sponsored by Vital and discounts of $10 \%$ for single bookings and $15 \%$ for group bookings are available - cite Vital/EAOM2010 on the application form. See www.eaom2010. com/programme/DCP or email admin@ eaom2010.com.

Reader response number 51

\section{ENVIRONMENTALLY FRIENDLY MONITOR TAPE}

Hu-Friedy has developed a new lead-free and latexfree monitor tape for the labelling of wrapped instrument cassettes. The environmentally friendly

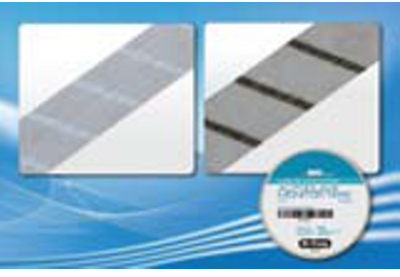
monitor tape eliminates the risk of lead contamination and protects patients and users who suffer from latex allergies.

The user can note down additional information (eg the sterilisation date and cassette contents) on the tape and it also serves as a reliable process indicator. Black stripes appear on the tape after the cassette has been autoclaved. This effectively rules out any confusion with cassettes which have not been sterilised. As it contains neither lead nor latex, the monitor tape is easily disposable after use. Contact info@hufriedy. eu for more information.

Reader response number 52

\section{IMPROVING PERIODONTAL HEALTH}

Colgate Total toothpaste contains a unique combination of triclosan, an antibacterial agent, along with a copolymer. The copolymer ensures the retention of the triclosan on the surface of the teeth and gingiva, by preventing dental plaque from reforming to provide 12 hour antibacterial protection.

In addition to patient samples, Colgate has waiting room posters for your practice to encourage your patients to seek advice on how to improve their gingival health, along with a patient information leaflet entitled

'Helpful tips to keep your gums healthy'. For further information contact the Colgate Customer Care Team on 01483401901. Reader response number 53
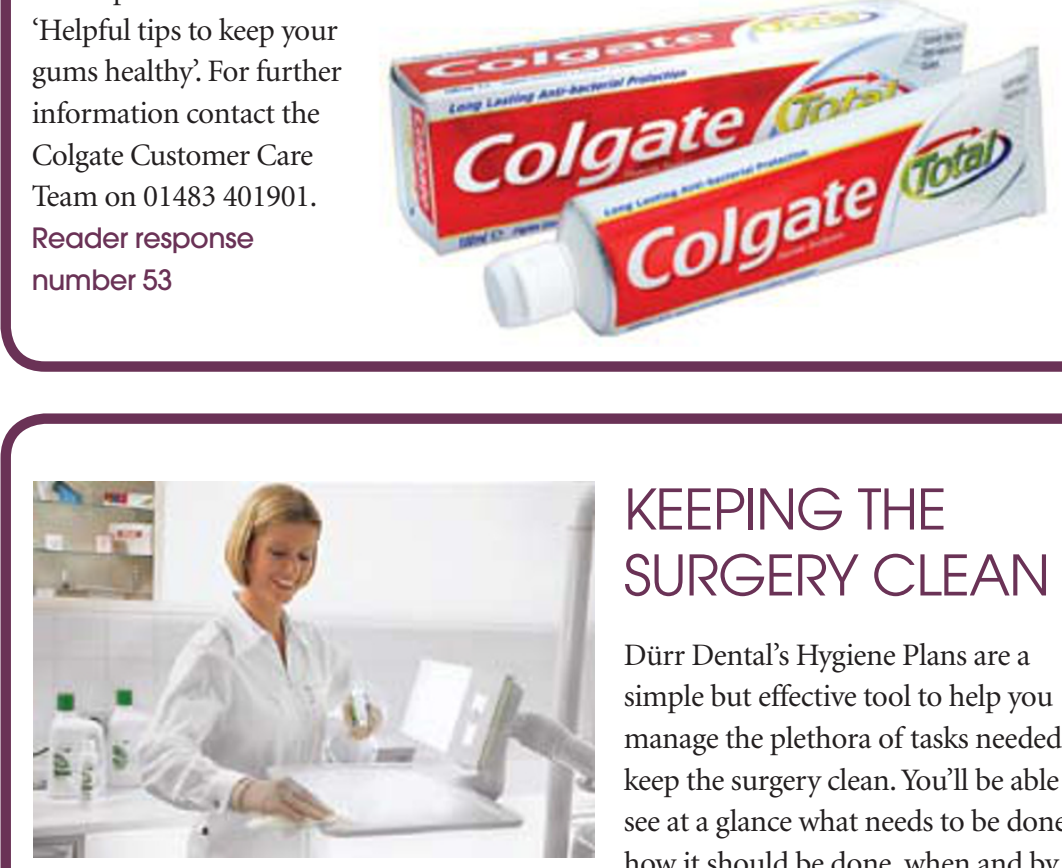

KEEPING THE SURGERY CLEAN

Dürr Dental's Hygiene Plans are a simple but effective tool to help you manage the plethora of tasks needed to keep the surgery clean. You'll be able to see at a glance what needs to be done, how it should be done, when and by

whom. You can easily delegate certain tasks to specific individuals as the 'Who' section is left blank so that you can fill in the name of the person responsible.

The chart is colour coded for easy use: blue for instruments, green for surfaces, pink for skin and hands, and yellow for special areas such as suction systems and amalgam separators. For a free Hygiene Plan write to Dürr Dental, 14 Linnell Way, Telford Way Industrial Estate, Kettering, Northants, NN16 8PS.

Reader response number 54 